\title{
PENGARUH PENYULUHAN SAFETY RIDING DENGAN MEDIA AUDIO VISUAL TERHADAP PENINGKATAN PERILAKU BERKENDARA
}

\author{
Dryo Saputro, Lina Handayani*, Maya Kusuma Dewi \\ Fakultas Kesehatan Masyarakat, Universitas Ahmad Dahlan \\ *correspondence, e-mail: linafkm@gmail.com Telp:_081330303420 \\ Dikirimkan 3 Mei 2019; Diterima 15 Mei 2019; Dipublikasikan Agustus 2019
}

\begin{abstract}
Indonesia is a country with high level of traffic accidents. Traffic accidents in Indonesia according to the World Health Organization is the third largest killer under coronary heart disease and tuberculosis. Traffic accidents are caused by several factors including human factors, vehicle factors, road factors, environmental factors and weather factors. Teenagers are one of the biggest contributors to traffic accidents. Age 13-18 years is the early teens where they just felt an interest in trying to ride a motorcycle. Teenagers think that they are mature enough to drive vehicles on the road, with the knowledge of shallow driving causing accidents. Traffic safety is greatly influenced by driver's discipline. Driver's discipline can increase the level of traffic safety. The purpose of this study is to determine the effect of providing audio visual safety riding counseling to the knowledge and attitude of driving. The research was a quasi-experimental with one-group pre-test post-test design. Respondent in this study was 70 Muhammadiyah 4 Yogyakarta high school students. The sample was gathered by purposive sampling technique. The instrument used was a questionnaire. The study began with a pre-test and then a video screening and conducted a post-test with the same questionnaire. The data analysis test were the parametric paired sample $T$ test, the non parametric Wilcoxon test. The results of non-parametric Wilcoxon test analysis obtained p value of o.ooo. The results showed that there was an influence of counseling with audio visual safety riding methods on knowledge. The results of the paired sample T-test test analysis obtained o.ooo which shows the effect of providing audio visual safety riding on attitudes. There is an effect of counseling using audio visual safety riding methods on students' knowledge and driving attitudes.
\end{abstract}

Keywords: Audio visual, safety riding, knowledge, attitude

\section{PENDAHULUAN}

Indonesia merupakan salah satu negara yang memiliki tingkat kecelakaan lalu lintas yang cukup tinggi. Kecelakaan lalu lintas di Indonesia merupakan pembunuh terbesar ketiga di bawah penyakit jantung koroner dan tubercolosis/TBC(1). Kecelakaan lalu lintas merupakan suatu peristiwa di jalan yang tidak diduga dan tidak disengaja melibatkan kendaraan dengan atau tanpa pengguna jalan lain yang mengakibatkan korban manusia dan kerugian harta benda(2). Kecelakaan lalu lintas juga disebabkan beberapa faktor yang menjadi penyebab dari kecelakaan lalu lintas antara lain faktor manusia, faktor kendaraan, faktor jalan (sarana prasarana), faktor lingkungan dan cuaca(3).

Keselamatan berlalu lintas sangat dipengaruhi oleh disiplin pengendara. Peningkatan disiplin pengendara dapat menabah tingkat keselamatan berlalu lintas(4). Prevalensi cedera akibatkan kecelakaan lalu lintas sepeda motor di Daerah Istimewa Yogyakarta sebanyak 39,2\%. Data kepolisian lima tahun terakhir menunjukkan angka kecelakaan di Provinsi D.I. Yogyakarta cukup tinggi. Terjadi 
1.039 kasus kecelakaan tahun 2006, dimana jumlah ini meningkat tiga kali lipat dibanding tahun 2005. Kematian akibat kecelakaan (cedera intracranial) menempati urutan kedua sebagai penyebab kematian di Yogyakarta(5).

Laporan Kepolisian Negara Republik Indonesia melalui Direktorat Lalu Lintas D.I. Yogyakarta melaporkan bahwa jumlah kecelakaan yang terjadi di lima kabupaten di Yogyakarta tahun 2015 sebanyak 4.313 kasus dan melibatkan 5.889 kendaraan bermotor. Polres Sleman melaporkan angka kejadian kecelakaan lalu lintas sebanyak 1.260 kasus dan yang melibatkan kendaraan bermotor sebanyak 1.637 dengan korban meninggal 160 orang, luka berat 30 orang dan luka ringan 1.850 orang. Menurut Direktorat Lalu Lintas D. I. Yogyakarta, salah satu faktor yang memengaruhi angka kecelakaan yang mengakibatkan cedera di Kabupaten Sleman adalah karena kepadatan penduduk, sementara penelitian di Gunung Kidul menunjukkan bahwa fasilitas kecelakaan lalu lintas disebabkan karena kondisi geografis dan tipe kecelakaan(6).

Remaja merupakan salah satu segmen terbesar penyumbang kecelakaan lalu lintas. Usia 13 - 18 tahun adalah usia remaja awal di mana mereka baru merasakan ketertarikan untuk mencoba mengendarai motor. Remaja berpikir merasa cukup dewasa untuk mengendarai kendaraan di jalan, tetapi dengan pengetahuan tentang berkendara yang dangkal sering menyebabkan terjadinya kecelakaan(7).

Berdasarkan hasil studi pendahuluan diketahui masih terdapat siswa yang masih melakukan pelanggaran seperti berkendara teralu kencang ketika keluar dari gerbang sekolah, spion yang terpasang tidak lengkap, tidak menyalakan lampu utama saat berkendara dan masih terdapat siswa yang tidak menggunakan helm. Pengetahuan mengenai keselamatan berkendara atau safety riding sangat diperlukan guna menanamkan kebiasaan dan perilaku berkendara yang selamat pada siswa usia remaja. Pemberian materi dengan media audio visual sebagai media belajar sangat diperlukan guna menambah pengetahuan serta pemahaman siswa SMA Muhammadiyah 4 Kota Yogyakarta mengenai perilaku safety riding, dengan terjadinya permasalahan tersebut maka peneliti tertarik untuk mengkaji lebih dalam mengenai "Pengaruh pemberian audio visual safety riding terhadap pengetahuan dan sikap berkendara yang aman dan selamat bagi para siswa SMA Muhammadiyah 4 Kota Yogyakarta”.

\section{METODE PENELITIAN}

Desain penelitian yang digunakan dalam penelitian ini adalah preeksperimen dengan rancangan one-group pre-test post-test design yang terdiri atas 1 variabel terikat yaitu pemberian media audio visual safety riding dan 2 variabel bebas yaitu pengetahuan dan sikap berkendara siswa. Penelitian ini dilakukan di SMA Muhammadiyah 4 Yogyakarta dengan sampel sebanyak 70 responden dengan menggunakan teknik purposive sampling, instrumen yang digunakan yaitu kuesioner. Analisis statistik yang digunakan adalah uji statistik parametric Paired sample T-test dan uji non parametric Wilcoxon.

\section{HASIL DAN PEMBAHASAN}

Distribusi frekuensi karakteristik responden berdasarkan usia dan jenis kelamin dapat dilihat pada Tabel 1. 
Tabel 1. Karakteristik Responden Berdasarkan Usia

\begin{tabular}{cccc}
\hline No. & $\begin{array}{c}\text { Usia } \\
\text { (tahun) }\end{array}$ & $\mathbf{n}$ & $\mathbf{\%}$ \\
\hline 1. & 16 & 39 & 55.7 \\
\hline 2. & 17 & 31 & 44.2 \\
\hline \multicolumn{2}{c}{ Jumlah } & 70 & $100 \%$ \\
\hline No. & $\begin{array}{c}\text { Jenis } \\
\text { Kelamin }\end{array}$ & $\mathbf{n}$ & $\mathbf{\%}$ \\
\hline 1. & Laki-laki & 38 & 54,2 \\
\hline 2. & Wanita & 32 & 45,7 \\
\hline \multicolumn{2}{c}{ Jumlah } & 70 & $100 \%$ \\
\hline
\end{tabular}

(Sumber: data primer terolah, 2018)

Tabel 1 menunjukkan bahwa responden lebih banyak berusia 16 tahun yaitu sebanyak 39 orang $(55,7 \%)$ dan responden laki-laki lebih banyak yaitu 38 orang $(54,2 \%)$.

Pada penelitian ini dilakukan pengukuran variabel pengetahuan dan sikap mengenai safety riding pada saat sebelum (pre) dan sesudah (post) diberikan penyuluhan menggunakan metode audio visual dapat dilihat pada Tabel 2 dan Tabel 3 sebagai berikut:

Tabel 2. Hasil Pre Test dan Post Test Variabel Pengetahuan Siswa

\begin{tabular}{|c|c|c|c|c|c|}
\hline \multirow{2}{*}{$\begin{array}{c}\text { Tingkat } \\
\text { pengetahuan }\end{array}$} & \multicolumn{2}{|c|}{ Pre test } & \multicolumn{2}{|c|}{ Post test } & \multirow[b]{2}{*}{ Selisih } \\
\hline & $\begin{array}{l}\text { Jumlah } \\
\text { (orang) }\end{array}$ & (\%) & $\begin{array}{l}\text { Jumlah } \\
\text { (orang) }\end{array}$ & (\%) & \\
\hline Tinggi & 27 & 38,6 & 38 & 54,3 & $11(15,71)$ \\
\hline Rendah & 43 & 61,4 & 32 & 45,7 & $11(15,71)$ \\
\hline
\end{tabular}

(Sumber: data primer terolah, 2018)

Tabel 2 menunjukkan hasil sebelum pemberian materi dengan media audio visual safety riding terkait pengetahuan berkendara yang aman dan selamat bagi para siswa SMA Muhammadiyah 4 Kota Yogyakarta menunjukkan bahwa pre test sebanyak 27 siswa $(38,6 \%)$ memiliki tingkat pengetahuan tinggi dan sebanyak 43 siswa $(61,4 \%)$ memiliki tingkat pengetahuan rendah. Hasil sesudah pemberian materi dengan media audio visual safety riding terkait pengetahuan berkendara yang aman dan selamat bagi para siswa SMA Muhammadiyah 4 Kota Yogyakarta menunjukkan bahwa sebanyak 38 siswa $(54,29 \%)$ memiliki tingkat pengetahuan tinggi dan sebanyak 32 siswa (45,71\%) memiliki tingkat pengetahuan rendah. Berdasarkan tabel 2 dapat diketahui bahwa terdapat peningkatan pada tingkat pengetahuan siswa sehingga terdapat pengaruh pemberian materi dengan media audio visual safety riding terhadap pengetahuan berkendara yang aman dan selamat bagi para siswa SMA Muhammadiyah 4 Kota Yogyakarta.

Berdasarkan analisis uji statistik didapatkan hasil bahwa tingkat pengetahuan dengan data yang tidak terdistribusi normal yaitu diketahui median nilai pre-intervensi adalah 10,00 dan post-intervensi median nilai pengetahuan adalah 15,00. Nilai median tingkat pengetahuan responden menunjukkan peningkatan yang cukup besar yaitu peningkatan mencapai 5,oo. Peningkatan nilai tersebut menunjukkan adanya peningkatan pengetahuan responden mengenai 
berkendara yang selamat bagi siswa SMA Muhammadiyah 4 Yogyakarta yang bermakna setelah dilakukan intervensi dengan pemberian materi dengan media audio visual safety riding.

Jumlah responden dengan tingkat pengetahuan yang tinggi tentang safety riding pada saat pre-intervensi sebanyak 27 orang $(38,6 \%)$, kemudian meningkat pada post-intervensi menggunakan media audio visual menjadi 38 orang (54,7\%), peningkatan pengetahuan siswa disebabkan penggunaan media audio visual safety riding membantu siswa untuk lebih mudah dalam menangkap dan memahami segala sesuatu yang disampaikan terkait safety riding, mulai dari materi sampai praktik yang ditampilkan dalam bentuk gambar, video dan suara yang mampu merespon indera penglihatan, pendengaran dan indera lainnya.

Kemudian, untuk responden dengan kategori tingkat pengetahuan rendah pada saat pre-intervensi sebanyak 43 orang $(61,4 \%)$, kemudian setelah dilakukan post-intervensi menjadi 32 orang (45,7\%). Penurunan yang terjadi pada pengetahuan rendah disebabkan oleh pemahaman siswa terkait safety riding yang telah meningkat, dari yang awalnya masih belum tahu atau belum paham menjadi lebih tahu dan paham. Peneltian ini sejalan dengan Azizah yang menyatakan bahwa penelitian dilapangan ditemukan responden yang memiliki pengetahuan kurang 63,8\% tidak aman dan selamat dalam berperilaku keselamatan berkendara (safety riding) lebih memahami safety riding serta tahu bagaimana dan apa saja yang harus dilakukan ketika hendak berkendara, selama berkendara dan setelah berkendara(8).

Berdasarkan hasil yang diperoleh pada pre-intervensi dan post-intervensi menggunakan media audio visual terdapat adanya peningkatan jumlah responden dengan pengetahuan yang semakin baik mengenai safety riding. Hal tersebut sejalan dengan penelitian yang dilakukan oleh Nandipinta dimana penelitian yang dilakukan diperoleh hasil bahwa dengan pemberian peragaan keamanan berkendara (safety riding) efektif untuk meningkatkan pengetahuan disiplin berlalu lintas(9). Pemberian peragaan cenderung lebih efektif dalam memicu otak untuk lebih mudah menangkap rangsangan dan mengingat segala sesuatu yang disampaikan melalui indera penglihatan, pendengaran dan lainnya. Menurut Dale dalam Arsyad (2015) menyatakan bahwa melalui indra pandang akan mengingat $75 \%$, melalui indra pendengaran akan mengingat $13 \%$ dan melalui indra lainnya akan mengingat $12 \%(10)$.

Hasil dari analisis Uji Non Parametric Wilcoxon diperoleh $p$ value o,ooo artinya hasil tersebut menunjukkan ada pengaruh pemberian video safety riding menggunakan media audio visual terhadap pengetahuan. Hal ini dikarenakan siswa telah diberikan edukasi tentang safety riding menggunakan media audio visual, dikarenakan dalam audio visual meliputi indera penglihatan dan indera pendengaran. Perolehan hasil dari belajar melalui indera pandang akan mengingat $75 \%$, melalui indera pendengaran akan mengingat $13 \%$ dan melalui indera lainnya akan mengingat $12 \%$. Penelitian ini sejalan dengan penelitian yang dilakukan Adhanudin yang menyatakan bahwa pengetahuan warga kampung Safety ditunjang dengan adanya pemberian materi secara berkala dengan cara sosialisasi seperti praktik keterampilan tentang berkendara menggunakan helm. Semua bentuk materi yang telah diberikan membuat pengetahuan warga tentang safety riding menjadi lebih baik(11). Penelitian ini tidak sejalan dengan penelitian yang 
dilakukan Prima yang menyatakan bahwa tidak ada hubungan antara pengetahuan safety riding dengan perilaku safety riding $p>0,05(12)$.

Siswa sebenarnya telah mengetahui beberapa hal terkait pelaksanaan safety riding seperti yang harus dilakukan sebelum, saat dan setelah berkendara, namun pada fakta dilapangan masih terdapat siswa yang bahkan tidak melakukan safety riding seperti melakukan pemeriksaan berkendara meliputi pengecekan rem, lampu kendaraan, pengecekan ban, menyalakan lampu di siang hari dan sebagainya. Hal tersebut disebabkan karena berberapa faktor yaitu kurangnya pengetahuan dan pemahaman terkait safety riding kemudian mengikuti trend yang salah seperti memodifikasi spion, knalpot, dan sebagainya serta sifat malas siswa dalam menggunakan atribut safety riding dan melakukan pengecekan motor sebelum berkendara.

Siswa sebagian besar sudah mengetahui bahwa penggunaan helm saat berkendara merupakan suatu hal yang sangat penting untuk keselamatan, hal ini sesuai dengan UU No.22 Tahun 2009 pasal 57 mengenai perlengkapan kendaraan bermotor dimana dalam Undang-Undang tersebut dijelaskan bahwa setiap kendaraan bermotor yaitu berupa helm Standar Nasional Indonesia (SNI), namun pada faktanya masih terdapat siswa yang tidak menggunakan helm ketika berkendara dan sebagian responden mengatakan bahwa jarak tempuh yang dekat membuat mereka tidak menggunakan helm(13). Tabel 3 :

Hasil pre tes dan post test variable sikap siswa dapat dilihat seperti pada

Tabel 3. Hasil Pre Test dan Post Test Variabel Sikap Siswa

\begin{tabular}{cccccc}
\hline Tingkat sikap & \multicolumn{2}{c}{ Pre test } & \multicolumn{2}{c}{ Post test } & \multirow{2}{*}{ Selisih } \\
\cline { 2 - 5 } & $\begin{array}{c}\text { Jumlah } \\
\text { (orang) }\end{array}$ & $(\%)$ & $\begin{array}{c}\text { Jumlah } \\
\text { (orang) }\end{array}$ & (\%) & \\
\hline Baik & 33 & 47,1 & 34 & 48,6 & $1(1,5)$ \\
\hline Buruk & 37 & 52,9 & 36 & 51,4 & $1(1,5)$ \\
\hline
\end{tabular}

(Sumber: data primer terolah, 2018)

Berdasarkan Tabel 3 hasil sebelum pemberian materi dengan media audio visual safety riding terkait sikap berkendara yang selamat bagi para siswa SMA Muhammadiyah 4 Yogyakarta menunjukkan bahwa sebanyak 33 siswa (47,1\%) memiliki sikap baik, dan sebanyak 37 siswa (52,9\%) memiliki sikap buruk. Hasil sesudah pemberian materi dengan media audio visual safety riding terkait sikap berkendara yang selamat bagi para siswa SMA Muhammadiyah 4 Kota Yogyakarta menunjukkan bahwa sebanyak 34 siswa $(48,6 \%)$ memiliki sikap baik dan sebanyak 36 siswa $(51,4 \%)$ memiliki sikap buruk. Berdasarkan tabel 3 dapat diketahui bahwa terdapat peningkatan skor pada sikap siswa sehingga terdapat pengaruh pemberian materia dengan media audio visual safety riding terhadap sikap berkendara yang aman dan selamat bagi para siswa SMA Muhammadiyah 4 Kota Yogyakarta.

Hasil analisis uji Non Parametric Wilcoxon pemberian materi dengan media audio visual safety riding terhadap pengetahuan siswa dapat dilihat pada Tabel 4 . 
Tabel 4. Hasil Uji Non Parametric Wilcoxon Pre Test dan Post Test Variabel Pemberian Media Audio Visual Terhadap Pengetahuan Siswa

\begin{tabular}{ccccc}
\hline Kelompok & Frekuensi & $\begin{array}{c}\text { Median } \\
\text { (Minimum- } \\
\text { Maksimum) }\end{array}$ & Rerata \pm SD & P \\
\cline { 1 - 4 } Pre-test & 70 & $10,00(7,00-15,00)$ & $10,27 \pm 2,042$ & 0,000 \\
\cline { 1 - 4 } Post-test & 70 & $15,00(3,00-19,00)$ & $14,04 \pm 4,069$ & \\
\hline
\end{tabular}

(Sumber: Data Primer Terolah, 2018)

Tabel 4 menunjukkan bahwa terdapat nilai median pre-test pengetahuan responden sebesar 10,00 dan nilai median post-test pengetahuan responden sebesar 15,00. Terdapat perbedaan nilai rata-rata sebesar 5,00. Hal tersebut menunjukkan bahwa terjadi peningkatan pengetahuan responden sesudah diberikan perlakuan menggunakan media audio visual. Hasil analisis statistik menunjukkan ada pengaruh pemberian audio visual safety riding menggunakan media audio visual terhadap pengetahuan responden tentang safety riding ( $p$ value $\mathrm{0}, \mathrm{000})$.

Hasil analisis uji Parametric sample T-test pemberian materi dengan media audio visual safety riding terhadap variabel sikap siswa dapat dilihat pada Tabel 5 .

Tabel 5. Hasil Uji Parametric Sample T-Test Pre Test dan Post Test Variabel Pemberian Media Audio Visual Terhadap Sikap Siswa

\begin{tabular}{cccc}
\hline Kelompok & Frekuensi & Rerata \pm SD & $\boldsymbol{P}$ \\
\hline Pre Test & 70 & $36,11 \pm 4,480$ & 0,000 \\
\hline Post Test & 70 & $40,08 \pm 3,903$ & \\
\hline
\end{tabular}

(Sumber: Data Primer Terolah, 2018)

Tabel 5 menunjukkan bahwa hasil rata-rata pre-test sikap sebesar 36,11 dan nilai rata-rata post-test sebesar 40,08. Terdapat perbedaan rata-rata sebesar 4,69. Hal tersebut menunjukkan bahwa terdapat peningkatan sikap responden sesudah diberikan perlakuan menggunakan media audio visual. Hasil analisis statistik menunjukkan bahwa terdapat pengaruh pemberian penyuluhan audio visual safety riding terhadap peningkatan sikap responden tentang safety riding ( $p$ value o,ooo).

Media audio visual memiliki keunggulan tersendiri dalam peningkatan pengetahuan untuk mendorong sikap responden menjadi lebih baik, keunggulan tersebut terletak pada penyajian yang tidak biasa mulai dari adanya gambar, video tentang safety riding serta suara yang mampu merespon otak untuk lebih cepat dan mudah dalam menangkap, mengingat serta menerapkan apa yang didapat dari indra penglihatan, pendengaran serta indra lainnya pada saat berkendara. Berdasarkan penelitian Notosiswoyo (2014) yang dilakukan pada siswa SLTA kelas I dan II pemutaran VCD dan pemberian leaflet dapat meningkatkan sikap pengendara sepeda motor terhadap pencegahan kecelakaan lalu lintas(14). Menurut Ruslan (2015) menyatakan bahwa sikap responden yang kurang baik tentang safety riding secara signifikan akan meningkatkan risiko timbulnya praktik safety riding yang kurang baik, sedangkan sikap yang baik tentang safety riding akan menimbulkan praktik safety riding yang baik pula dikarenakan sudah 
memiliki kesadaran bahwa dengan menerapkan praktik cara berkendara yang aman sehingga dapat terhindar dari kemungkinan terjadinya kecelakaan(15).

Pada pre-intervensi terdapat sebanyak 33 orang (47,1\%) memiliki tingkat sikap yang baik, kemudian meningkat pada post-intervensi menggunakan media audio visual menjadi 34 orang (48,6\%). Video yang menggambarkan mengenai sikap safety riding merupakan faktor yang mendorong keinginan responden untuk melakukan hal tersebut, mulai dari apa yang tidak boleh dilakukan saat berkendara sampai sikap berkendara yang safety. Selanjutnya, untuk responden dengan kategori sikap yang buruk pada saat pre-intervensi sebanyak 37 orang (52,9\%), kemudian setelah dilakukan post-intervensi menjadi 36 orang $(51,4 \%)$. Penurunan sikap yang buruk dipengaruhi oleh keinginan responden untuk benarbenar berubah dari yang buruk menjadi baik serta rasa takut akan kecelakaan membuat responden bersikap lebih safety. Berdasarkan hasil yang diperoleh pada pre-intervensi dan post-intervensi menggunakan media audio visual terdapat adanya peningkatan jumlah responden dengan sikap yang semakin baik mengenai safety riding. Menurut Ruslan (2015) mengatakan bahwa sikap responden yang kurang baik tentang safety riding secara signifikan akan meningkatkan risiko timbulnya praktik safety riding yang kurang baik, sedangkan sikap yang baik tentang safety riding akan menimbulkan praktik safety riding yang baik pula karena sudah memiliki kesadaran bahwa dengan menerapkan praktik cara berkendara yang aman sehingga dapat terhindar dari kemungkinan terjadinya kecelakaan(15).

Peningkatan sikap responden dibuktikan dengan hasil sig dari analisis pairet sample T-test yaitu o,ooo yang menunjukkan bahwa adanya pengaruh pemberian audio visual safety riding terhadap peningkatan sikap tentang berkendara yang aman dan selamat bagi siswa SMA Muhammadiyah 4 Yogyakarta. Media audio visual dapat meningkatkan pengetahuan untuk mendorong sikap responden menjadi lebih baik. Penelitian ini sejalan dengan penelitian yang dilakukan Notosiswoyo yang dilakukan pada siswa SLTA kelas I dan II pemutaran VCD dan pemberian leaflet dapat meningkatkan sikap pengendara sepeda motor terhadap pencegahan kecelakaan lalu lintas(16). Penelitian ini diperkuat dengan penelitian yang dilakukan Ariwibowo yang meyatakan bahwa terdapat hubungan antara sikap terhadap praktik safety riding $(P=0,001)(17)$.

Hasil penelitian ini sesuai Indriani (2011) bahwa penggunaan media audio visual dianggap mampu menarik perhatian dan motivasi belajar para siswa yang akan berpengaruh pada hasil belajar siswa. Keberhasilan pembelajaran ditandai dengan perolehan pengetahuan, ketrampilan dan sikap positif pada diri individu sesuai dengan tujuan yang diharapkan(18).

Namun kenyataan di lapangan, seorang siswa merupakan seseorang yang berpendidikan, namun masih terdapat siswa yang tidak bersikap disiplin dalam berkendara, seperti tidak menyalakan lampu utama, tidak menyalakan lampu sign ketika berbelok, tidak menggunakan jaket, penggunaan motor yang tidak dilengkapi spion, tidak membawa SIM/STNK, serta masih terdapat yang tidak menggunakan helm karena malas dan jarak tempuh yang dekat. Sesuai UndangUndang No.22 Tahun 2009 pasal 203 ayat 2 bahwa program nasional keselamatan lalu lintas dan angkutan jalan diantarannya yaitu tentang keselamatan berkendara 
(safety riding), seperti larangan mendengarkan musik saat mengendarai sepeda motor, larangan menerima telepon saat mengendarai sepeda motor, larangan merubah warna sepeda motor dan harus sesuai warna di STNK, wajib menyalakan lampu pada siang dan malam hari, dilarang merokok saat mrngendarai sepeda motor, wajib menggunakan helm Standar Nasional Indonesia (SNI) serta membawa surat kelengkapan seperti surat izin mengemudi (SIM) dan STNK.

Dalam berkendara sangat diperlukan etika dan adab sopan santun di jalanan. Hal tersebut untuk meminimalisir terjadinya kecelakaan lalu lintas. Namun di lapangan masih terdapat siswa pengendara sepeda motor yang tidak safety ketika berkendara seperti, saling serobot, tidak menyalakan lampu sign ketika berbelok, keluar pagar sekolah dengan ugal-ugalan ketika pulang sekolah, tidak menggunakan helm. Untuk meminimalisir kejadian yang tidak menyenangkan saat berkendara, seperti kecelakaan atau mencelakakan orang lain dengan selalu pastikan kondisi fisik dan jiwa yang sehat, lakukan pemanasan sedikit sebelum berangkat ke tujuan, pastikan sepeda motor yang akan digunakan benar-benar siap selama dalam perjalanan, mulai dari kesiapan kondisi mesin kendaraan, ban, rem, kopling, oli, handle gas, lampu depan, lampu rem, sign, rantai, busi, bahan bakar dan surat-surat (SIM dan STNK), gunakan helm full face atau helm standar (SNI) baik bagi pengemudi maupun pembonceng, menggunakan kacamata dengan Ultra Violet (UV) protection di siang hari agar tidak silau dan pandangan mata lebih jelas, pengendara menggunakan jaket, sepatu, sarung tangan, tidak membawa muatan lebih dari 2 orang, mematuhi rambu-rambu lalu lintas sepanjang perjalanan, tidak mengambil jalur khusus pejalan kaki / sepeda, tidak menaiki trotoar untuk pejalan kaki karena hal ini sangat tidak beretika, menyalakan lampu utama pada siang hari, menggunakan lajur jalan paling kiri saat kecepatan di bawah $40 \mathrm{~km} / \mathrm{jam}$, tidak menggunakan knalpot racing karena hal tersebut dapat mengganggu kenyamanan orang lain, dan selalu berdoa memohon keselamatan kepada Allah sebelum memulai perjalanan.

\section{KESIMPULAN DAN SARAN}

Berdasarkan hasil penelitian ini dapat disimpulkan bahwa adanya peningkatan pada tingkat pengetahuan dan sikap siswa sehingga terdapat pengaruh pemberian audio visual safety riding terhadap pengetahuan dan sikap berkendara siswa SMA Muhammadiyah 4 Yogyakarta.

Pihak sekolah sebaiknya melakukan pengawasan terhadap siswa yang mengendarai sepeda motor ke sekolah dan perlu menumbuhkan sikap siswa mengenai safety riding dengan sosialisasi mengenai perilaku safety riding serta aturan-aturan lalu lintas dengan bekerja sama dengan pihak kepolisian satuan lalu lintas. Siswa hendaknya dapat lebih meningkatkan pengetahuan tentang safety riding dengan mencari informasi lebih mendalam di media elektronik dan menerapkan sikap safety riding di sekolah maupun di jalan raya untuk mengurangi angka kecelakaan akibat berkendara. Pihak kepolisian diharapkan lebih memperketat pengawasan dengan mengadakan sweeping bagi siswa yang tidak memiliki SIM, khususnya di sekitar wilayah sekolah. Peneliti selanjutnya perlu melakukan penelitian yang mendalam terkait faktor-faktor yang memengaruhi siswa berkendara tanpa memiliki SIM serta kerjasama tim sangat diperlukan sekali dalam mendukung berjalannya penelitian eksperimen ini. 
Dengan menaati peraturan yang ada maka pengendara sepeda motor ikut serta dalam menurunkan angka kecelakaan lalu lintas.

\section{REFERENSI :}

1. World Health Organization. Road Traffic Injuries. 2011. Tersedia di http://www.who.int. (diakses pada tanggal 18 maret 2018).

2. Badan Pusat Statistik. Statistik Transportasi Darat 2016. Jakarta. 2016.

3. UU RI Nomor 22 Tahun 2009 Tentang Lalu Lintas dan Angkutan Jalan. Jakarta, Sekertariat Negara RI. 2009.

4. Kurniati, S., Sihombing. Keselamatan Berlalu lintas di Kota Bogor Traffict Safety in Bogor. Jurnal Manajemen Transportasi dan Logistik. 2017;04(1):75-87.

5. Dinkes. Profil Kesehatan Provinsi D. I. Yogyakarta Tahun 2012, Dinas Kesehatan DIY. 2012.

6. Isfandyari, A., Lazuardi. Fatalitas dan Analisis Spasial Lokasi Rawan Kecelakaan Lalu Lintas di Kabupaten Gunung Kidul. Berita Kedokteran Masyarakat. Journal of community medicine and public health. 2018; 34(2):50-54.

7. Lim, S. Safety Driving Guidance Book. Buku Pedoman Keselamatan Berkendara. Abiyah Pratama Press. Bogor. 2009:38-41.

8. Azizah. Faktor yang Berhubungan dengan Perilaku Keselamatan Berkendara (Safety riding) pada Mahasiswa (Studi pada Mahasiswa FMIPA UNES Angkatan 2008-2015). Skripsi Universitas Negeri Semarang. Semarang. 2016.

9. Nandipita, N. Pengaruh Peragaan Keamanan Berkendara (Safety Riding) Terhadap Pengetahuan Disiplin Berlalu Lintas Pada Siswa Kelas V SD Ta'Mirul Islam Surakarta. Skripsi Universitas Muhammadiyah Surakarta. Surakarta. 2012.

10. Arsyad, A. Media Pengajaran. Jakarta: Raja Grafindo Persada. 2015.

11. Adhanuddin,Y., Ekawati, Wahyuni, I. Analisis Perilaku Safety riding pada Warga Kampung Safety di Kelurahan Pandean, Lamper, Kota Semarang. Jurnal Kesehatan Masyarakat Universitas Diponegoro. Semarang. 2017;5(3).

12. Prima, DW, Kurniawan Bina, Ekawati. Faktor-Faktor Yang Berhubungan Terhadap Perilaku Safety Riding Pada Mahasiswa Fakultas X Universitas Dipenegoro, Jurnal kesehatan masyarakat. 2016;3(3).

13. UU RI Nomor 22 Tahun 2009 Tentang Lalu Lintas dan Angkutan Jalan. Jakarta. Sekertariat Negara RI. 2009.

14. Notosiswoyo, M. 2014, Penggunaan VCD dan Leaflet untuk Peningkatan Pengetahuan, Sikap dan Perilaku Siswa dalam Pencegahan Kecelakaan Sepeda Motor. Jurnal Kesehatan Masyarakat. volume 8 No 8

15. Ruslan, Z. Hubungan antara Tingkat Pendidikan, Pengetahuan dan Sikap dengan Praktik Safety riding Awareness pada Penggojek Sepeda Motor di Terminal Giwangan Kota Yogyakarta. Skripsi Universitas Ahmad Dahlan Yogyakarta. Yogyakarta. 2015.

16. Notosiswoyo, M. Penggunaan VCD dan Leaflet untuk Peningkatan Pengetahuan, Sikap dan Perilaku Siswa dalam Pencegahan Kecelakaan Sepeda Motor, Jurnal Kesehatan Masyarakat. 2014;8 (8).

17. Ariwibowo. Hubungan Antara Umur, Tingkat Pendidikan, Pengetahuan, Sikap Terhadap Praktik Safety riding Awareness pada Pengendara Ojek Sepeda Motor di Kecamatan Banyumanik, Jakarta. Jurnal Kesehatan Masyarakat. 2013;2(1):215-222 
18. Indriani, D. Ragam alat bantu media pengajaran. Diva Prees. Yogyakarta. 2011. 